\title{
Latitudinal variation in herbivory: hemispheric asymmetries and the role of climatic drivers
}

\author{
Shuang Zhang, Yuxin Zhang and Keming Ma* \\ State Key Laboratory of Urban and Regional Ecology, Research Center for Eco-Environmental Sciences, Chinese \\ Academy of Sciences, Beijing 100085, China
}

\begin{abstract}
Summary
1. In the past, it was widely accepted that herbivory decreased with latitude. However, several empirical studies have failed to support this hypothesis, leading to strong debate. In addition to providing a quantitative assessment of the latitudinal gradient in herbivory, our study aims to provide new information about the role of climatic factors in shaping the latitudinal gradient in herbivory.

2. Through the collection and analysis of published data on herbivory, we tested the latitudinal herbivory hypothesis (LH hypothesis) and the relationship of temperature and precipitation to herbivory.

3. Based on 1890 data points distributed world-wide from more than 1000 plant species, our results show that herbivory decreased with latitude and increased with temperature only in the Northern Hemisphere. In contrast, in the Southern Hemisphere, herbivory did not have a relationship with latitude and tended to decrease with temperature.

4. Synthesis. This study shows the LH hypothesis is supported only in the Northern Hemisphere and highlights the importance of temperature in explaining the pattern of herbivory at the global scale. These possible hemispheric asymmetries in herbivory should not be overlooked in future studies.
\end{abstract}

Key-words: biotic interactions, climate, growth form, latitude, plant-herbivore interactions, precipitation, temperature

\section{Introduction}

It has been accepted widely that biotic interactions become stronger as latitude decreases (Dobzhansky 1950; Janzen 1970; Schemske et al. 2009), and herbivory, the most important pathway for energy flow from plants to higher trophic levels, has been assumed to be higher at lower latitudes (Coley \& Barone 1996). Recent studies, however, have suggested that the validity of this assumption should be reconsidered (Moles et al. 2011a; Onoda et al. 2011). A newly published study showed that depending on life history and the type of organisms interacting latitude may have or not a strong impact in levels of herbivory (Zhang, Zhang \& Ma 2015).

Nearly twenty years ago, a review found that the level of herbivory was significantly higher in the tropics than in temperate regions (Coley \& Barone 1996). This study served as the foundation for the latitudinal herbivory hypothesis ( $\mathrm{LH}$ hypothesis). A number of studies have tested this hypothesis and have found a negative (Coley \& Aide 1991; Travers-Martin \& Muller 2008; Adams et al. 2009a; Pennings et al. 2009; Salazar \& Marquis 2012), positive (Lowman 1984; Gaston et al. 2004; Adams \& Zhang 2009; Adams et al.

*Correspondence author: E-mail: mkm@rcees.ac.cn 2009b), mixed (Anstett, Naujokaitis-Lewis \& Johnson 2014; Kim 2014; Moreira et al. 2015) or no relationship between latitude and herbivory (Andrew \& Hughes 2005; Sinclair \& Hughes 2008; Feller et al. 2013; Becerra 2015). Although the findings of these studies are inconsistent, the LH hypothesis has been regarded as a definitive conclusion in many cases, rather than as a hypothesis (Moles et al. 2011a). The latitudinal resistance hypothesis of plants (LR hypothesis) was developed on the basis of this conclusion (Rasmann \& Agrawal 2011). However, a recent meta-analysis found that, in fact, only $37 \%$ of related studies supported the LH hypothesis, with a non-significant effect size overall (Moles et al. 2011a). Another study that included 301 species from 75 sites worldwide found that tropical plants have no higher levels of resistance to herbivory than do plants from higher latitudes (Moles et al. 2011b). Further, another global analysis also found that leaves of tropical plants are not mechanically more resistant than are those of temperate plants (Onoda et al. 2011). A newly published study that included 452 tree species found that the LH hypothesis was supported for evergreen species, but not for species with short leaf life spans (Lim, Fine \& Mittelbach 2015). These studies suggest that the LH hypothesis is far from definitive and that the validity of the hypothesis should be reevaluated (Johnson \& Rasmann 2011; Moles et al. 2011a). 
In testing the LH hypothesis, it is undeniably important to rely on a standardized methodology in order to make a fair comparison of levels of herbivory (Adams \& Zhang 2009). However, standardized sampling has its limits: with only a few species and study sites in each study, the generalizability of the conclusions is questionable, and the contradictory findings in different studies are difficult to explain (Moles et al. 2011a; Kim 2014). In fact, if the LH hypothesis is indeed important, there should be a general latitudinal gradient in herbivory at the community level, regardless of the differences in species composition.

The role of climatic factors in shaping the latitudinal gradient in herbivory has not been well evaluated (Moles et al. 2011a; Lim, Fine \& Mittelbach 2015). Both temperature and precipitation are associated with latitude and have significant effects on herbivore-plant interactions (Coley \& Barone 1996; Bale et al. 2002). Although recent studies have confirmed the relationship of leaf traits with temperature and precipitation (Onoda et al. 2011; Pearse \& Hipp 2012; Moles et al. 2014), only a few studies have fitted herbivory with temperature and precipitation directly in tests of the LH hypothesis, also with mixed results. For example, in four widespread tree species, herbivory decreased with temperature across a $17^{0}$ latitudinal gradient, in contrast to the theoretical prediction (Adams \& Zhang 2009). Another study with a $16^{0}$ latitudinal gradient showed that the temperature-herbivory relationship depended on the feeding guild (generalist or specialist) of the herbivores, and temperature explained more variation in herbivory than did latitude and precipitation (Anstett, Naujokaitis-Lewis \& Johnson 2014). A newly published study found more complicated patterns: along a $5^{0}$ latitudinal gradient, seed herbivory decreased with temperature, but leaf herbivory was affected by unknown latitude-associated factors, neither temperature nor precipitation (Moreira et al. 2015). Therefore, the role of climatic factors in shaping the latitude-herbivory relationship has been studied poorly, especially at the global scale.

In this study, based on data collected from published data sets and other literature, we asked two questions: (i) Is there a general pattern of herbivory across latitudinal gradients? and (ii) How do climatic factors (temperature, precipitation) relate to the latitudinal variation in herbivory?

\section{Materials and methods}

\section{LITERATURE SEARCH AND DATA COLLECTION}

To make the data more comparable, we included only studies that used the percentage of leaf area damaged by herbivores as the measure of herbivory. This is also the method used most commonly to measure herbivory (Andrew, Roberts \& Hill 2012). We collected the data on leaf herbivory from published data sets (Kozlov, Zverev \& Zvereva 2014; Turcotte et al. 2014b) and other literature. In addition to the data sets, we used 'herbivory', 'leaf area loss', 'leaf damage', 'defoliation', 'folivory' and 'plant-herbivore interaction' as keywords in searches of the Web of Science and Google Scholar. The deadline for the search was 30 November 2014.

\section{SELECTION CRITERIA AND DATA ACQUISITION}

We collected data according to several criteria: (i) to maintain consistency with the data sets cited (Kozlov, Zverev \& Zvereva 2014; Turcotte et al. 2014b), herbivory was measured as the percentage of leaf area consumed by herbivores; (ii) only data capable of representing most of the damage a leaf endures in its lifetime were included. For example, data that quantified accumulated damage present on mature leaves, data collected at the end of the growing season and data summed damage of individual leaves over one month or more were included (Turcotte et al. 2014b). Daily herbivory rates in the cited data set were excluded (Turcotte et al. 2014b); (iii) for experimental studies, only the control data were included; (iv) if herbivory was measured in a time series, the data of the last time or the mean value of the various time samples was preferred, and (v) only observations conducted in the field were considered; those conducted in glasshouses or laboratories were excluded. The mean, standard error/ deviation and sample size were extracted from texts, tables or figures. For data expressed in figures, the UTHSCSA Image Tool (University of Texas, USA) was used to obtain exact values. Information on the latitude and longitude of the study site and the growth form of the study species was collected. Studies with no clear information on the coordinates of the study sites or with no clear information about the study sites were excluded. Climatic factors - mean annual temperature (MAT) and mean annual precipitation (MAP) - were obtained from the original literature or information about the study sites found through web searches. If this information was not available, climate data were extracted from the CRU CL 2.0 data set - a set of global climate grids with $10 \mathrm{~min}$ spatial resolution (New, Hulme \& Jones 1999).

\section{DATA ANALYSES}

Because approximately half of the data points collected had no clear standard deviation or error, a weighted regression would exclude these points. We preferred to use the unweighted mean herbivory for each data point in our analyses, as in the analyses in two previous studies (Turcotte et al. 2014b; Lim, Fine \& Mittelbach 2015). This criterion allowed inclusion of as many species and study sites as possible in our analyses. To maintain the independence of data for the same species, prior to the analyses, we averaged the herbivory data for a given species conducted at the same site within a reference.

The herbivory data were logit transformed, and data points with zero values $(n=21)$ were excluded in the analyses due to the difficulty of using these values in a regression (Lim, Fine \& Mittelbach 2015), and the proportion of zeros had no significant relation with latitude, MAT and MAP (Logistic regression, all $P$ values $>0.2$ ). Then, the data were analysed in two steps. First, to test the generality of the LH hypothesis, a linear mixed-effect model was used to fit the relationship between herbivory and latitude, with latitude and the interaction of latitude with hemisphere as fixed-effect terms and species and study location as the random-effect terms. We included the interaction term between hemisphere and latitude in the model to allow for different patterns in the Northern and Southern Hemispheres. Then, we performed a full model to evaluate simultaneously the effects of different factors on herbivory, including latitude, hemisphere, MAT, MAP, the growth form of plants and all interactions among them. Species and study location were set as random-effect factors in the model to account for interspecific and inter-site variations in herbivory that were not explained by the fixed effects (Moles et al. 2014). Study sites without clear MAT or MAP values were excluded in this analysis. The growth form of the plants was set as one of the 
fixed-effect terms because a previous study found that woody plants generally suffered significantly higher levels of herbivory compared to non-woody species (Turcotte et al. 2014a). Species and study location were set as random-effect terms to account for interspecific and inter-site variations in herbivory that were not explained by the fixed effects (Moles et al. 2014).

This model helped us test whether or not latitude was a significant predictor of herbivory after other random factors were taken into account, and to tease out the effects of temperature and precipitation on herbivory (Onoda et al. 2011). Model simplification was conducted based on the Akaike information criterion (AIC value). Variables were removed from the full model until a minimal, best-fit model with the lowest AIC values was obtained. The proportion of variance explained by the fixed terms was calculated as $R_{f}^{2}=\left(\sum \sigma_{f}^{2}\right) /\left(\sum \sigma_{f}^{2}+\sum \sigma_{r}^{2}+\sigma_{\varepsilon}^{2}\right)$, with the numerator as the sum of the variance calculated from fixed components and the denominator as the sum of the variance for fixed, random and error terms (Nakagawa \& Schielzeth 2013). Compared to ordinary regression, the results of our analyses were more conservative, because the mixedeffect model treated much of the variations as the effects of random factors (the degrees of freedom in the test were reduced greatly). All of the analyses above were conducted by the Mixed Procedure in SAS 9.3.

We also conducted a phylogenetic, generalized least squares regression model (PGLS) to account for the possible effects on our analyses of evolutionary relationships among species. The species-level phylogeny was generated from a supertree using Phylomatic (version 3.0, stored tree '20120829') (Webb \& Donoghue 2005). Divergence times in the trees were calculated using the BLADJ algorithm in Phylocom (Webb, Ackerly \& Kembel 2008). Because the number of trait data in the regression must be equal to the number of tips in the tree, only one data point can be included for each species. To include species that were studied at multiple locations, a resampling process was conducted. In this process, for a given species, one site was randomly selected, and the data for this site were used in the analyses. This resampling process was repeated for 1000 times, and each time, the PGLS analysis was conducted separately. The re-samplings were conducted by the SURVEYSELECT Procedure in SAS 9.3. The PGLS analyses were performed using the 'phylolm' package in R (Ho \& Ané 2014), and the phylogenetic models for the error term were selected based on the AIC values.

\section{Results}

In total, 1890 data points were collected from 291 publications. About two-thirds of the data points $(n=1221)$ were based on one published data set (Turcotte et al. 2014b), 39 were based on a second published data set (Kozlov, Zverev \& Zvereva 2014), and the remainder were collected from other published literature (see Supplementary materials for the data set and the list of literature). The data set included 166 families and more than 1000 species from 728 locations distributed world-wide (Fig. 1). The mean herbivory level was $8.79 \%$ across all species $(\mathrm{SE}=0.25, n=1890)$. On average plants in the Southern Hemisphere (mean $=12.04 \%$,

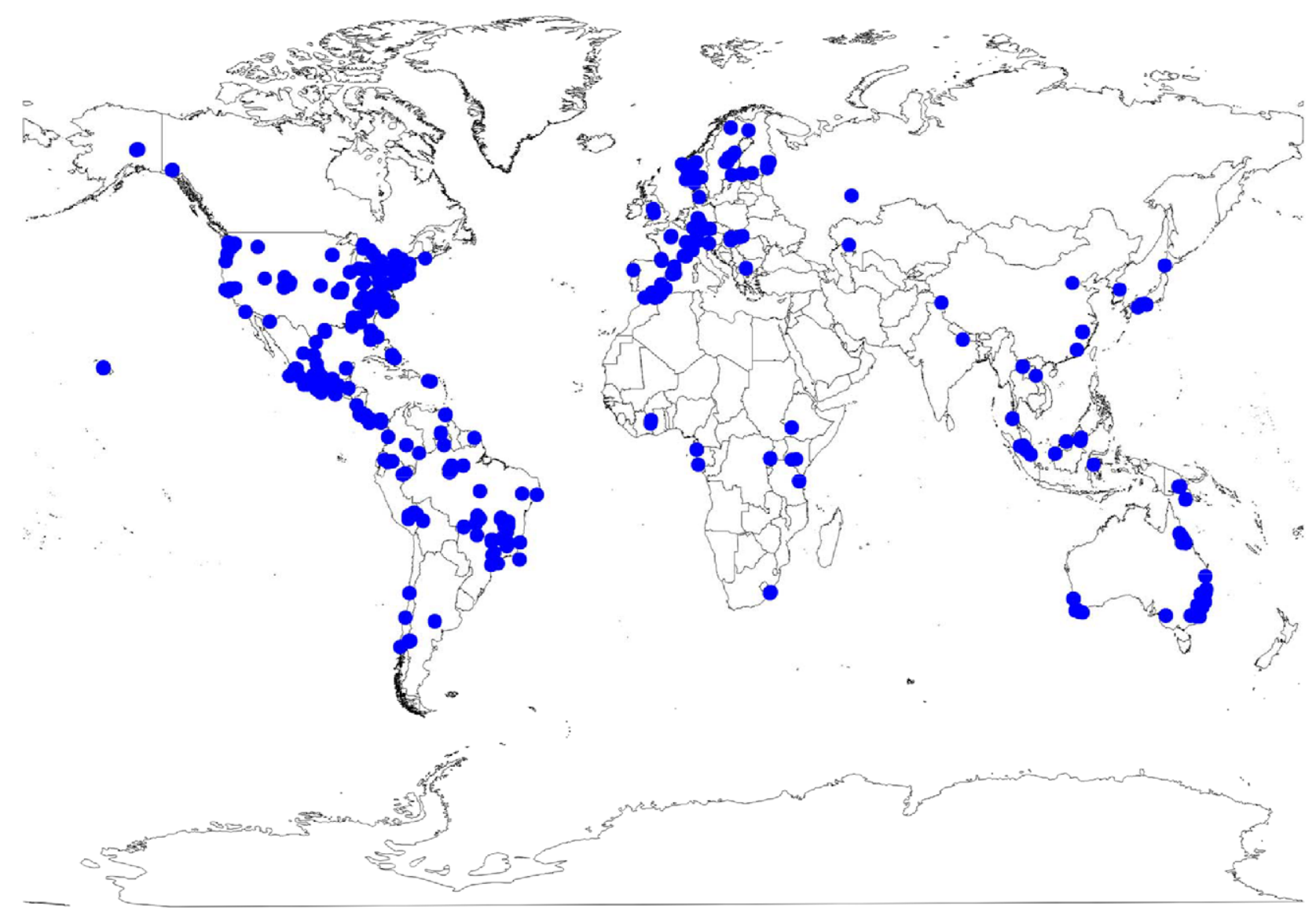

Fig. 1. Distribution of the study sites $(n=728$ locations). 

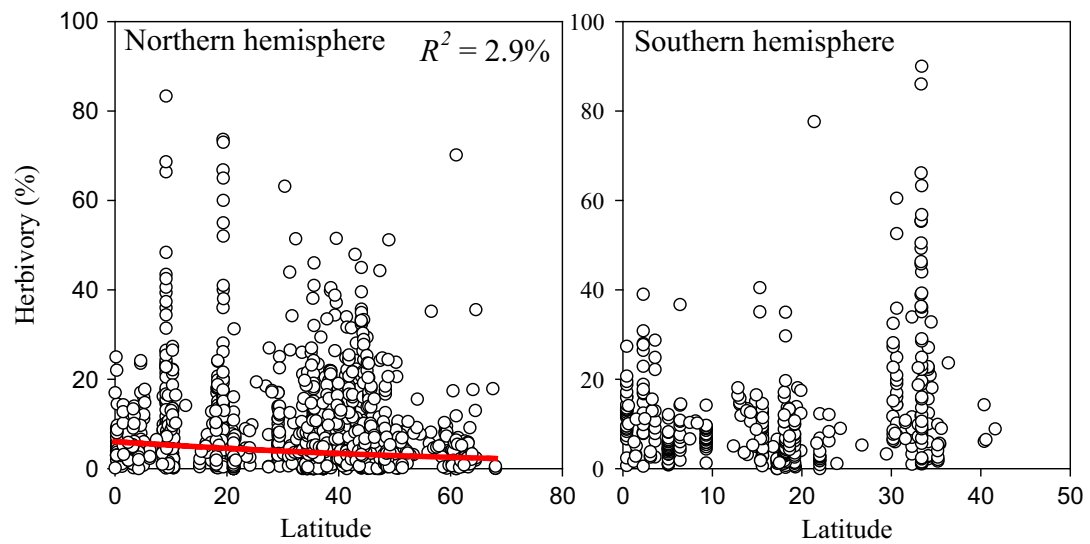

Fig. 2. The relationships between herbivory and latitude in the Northern and Southern Hemispheres.

$\mathrm{SE}=0.65 \%, n=392)$ had a 1.5 times higher level of herbivory than plants in the Northern Hemisphere (mean $=7.94 \%, \mathrm{SE}=0.26 \%, n=1498$ ). Study sites in the Southern Hemisphere had significantly higher levels of MAT and MAP than the sites in the Northern Hemisphere (Fig. S1 in Supporting information).

Herbivory was significantly affected by the interaction between hemisphere and latitude $\left(F_{1,257}=22.64\right.$, $P<0.0001)$, but not by latitude $\left(F_{1,257}=0.06, P=0.8077\right)$. It decreased significantly with latitude in the Northern Hemisphere $\left(t=-2.68\right.$, d.f. $\left.=201, P=0.0081, R^{2}=0.029\right)$, but did not show a relationship with latitude in the Southern Hemisphere $(t=1.41$, d.f. $=50, P=0.1636$, Fig. 2$)$. In the Northern Hemisphere, the mean herbivory level in tropical regions was $3.3 \%$ higher than in non-tropical regions $\left(F_{1,202}=9.98, P=0.0018\right)$. In comparison, in the Southern Hemisphere, a contrasting pattern was detected and the mean herbivory level in non-tropical regions was $10.1 \%$ higher than in tropical regions $\left(F_{1,51}=5.78, P=0.0198\right.$, Fig. S2 $)$.

The best-fit model (AIC $=5273$, compared to AIC $=5598$ of the full model) included the interaction between MAT and hemisphere $\left(F_{2,255}=9.68, P<0.0001\right)$, and the interaction between growth form and hemisphere $\left(F_{3,255}=10.01\right.$, $P<0.0004)$ as explanatory variables for the global variation of herbivory. The model accounted for $72.1 \%$ of the variation in herbivory, and $25.0 \%$ of this variation could be explained by fixed terms. Species and study site accounted for $19.7 \%$ and $27.4 \%$ of the variations in herbivory, respectively. In the Northern Hemisphere, herbivory increased with MAT (t $=3.91$, d.f. $\left.=201, P=0.0001, R^{2}=0.036\right)$ and woody species had a higher level of herbivory than non-woody species $\left(F_{1,201}=14.6, P=0.0002\right)$. In contrast, in the Southern Hemisphere, herbivory tended to decrease with MAT $\left(t=-2.07\right.$, d.f. $\left.=50, P=0.0433, R^{2}=0.026\right)$, and growth form did not have a significant effect on herbivory $(P>0.5)$ (Fig. 3).

At a global scale, 994 species were included in the PGLS analyses. The Lambda model had the lowest AIC values in the PGLS analyses. In all the 1000 replications, we detected different latitude/MAT-herbivory relationships between the Northern and Southern Hemispheres (Fig. S3). These results indicated that our main findings are unlikely to change when the evolutionary relationships among species were taken into account.

\section{Discussion}

Our synthesis of leaf herbivory effects from more than 1000 species and 728 locations world-wide found that the $\mathrm{LH}$ hypothesis was supported only in the Northern Hemisphere, even when the effects of various random factors and evolutionary relationships among species were taken into account. But in the Southern Hemisphere, herbivory did not show a clear relationship with latitude. We found that, compared to precipitation, temperature is a better predictor of herbivory, but with contrasting patterns between the two hemispheres. These findings suggest the existence of hemispheric asymmetries in herbivory and highlight the importance of temperature in explaining the global patterns of herbivory.

Our findings in the Northern Hemisphere are consistent with the prediction of the LH hypothesis. The findings of this study differ from those obtained in a previous meta-analysis, but which pooled the results of the Northern and Southern Hemispheres (Moles et al. 2011a). Another possible reason for this difference may be the fact that the previous review only included data from studies spanning at least two sites at different latitudes, and they focused on the effect sizes from the different studies (high- vs. low-latitude herbivory for each study), but not on the individual data points (Moles et al. 2011a). Through a re-inspection of the studies used in the previous meta-analysis (Moles et al. 2011a; Appendix S1), we found that, in the Northern Hemisphere, 38.7\% (12 of 31) of the studies showed a significant negative relationship between herbivory and latitude, and this relationship was found in only $16.7 \%$ (1 of 6 ) studies conducted in the Southern Hemisphere. Therefore, based on current studies, it seems likely that the LH hypothesis is more suitable in the Northern Hemisphere. The interspecific and inter-site differences contributed to a large proportion of the variations in herbivory in our study, and this may be an important factor in the controversy and mixed results of previous studies conducted in the Northern Hemisphere (Adams \& Zhang 2009; Adams et al. 

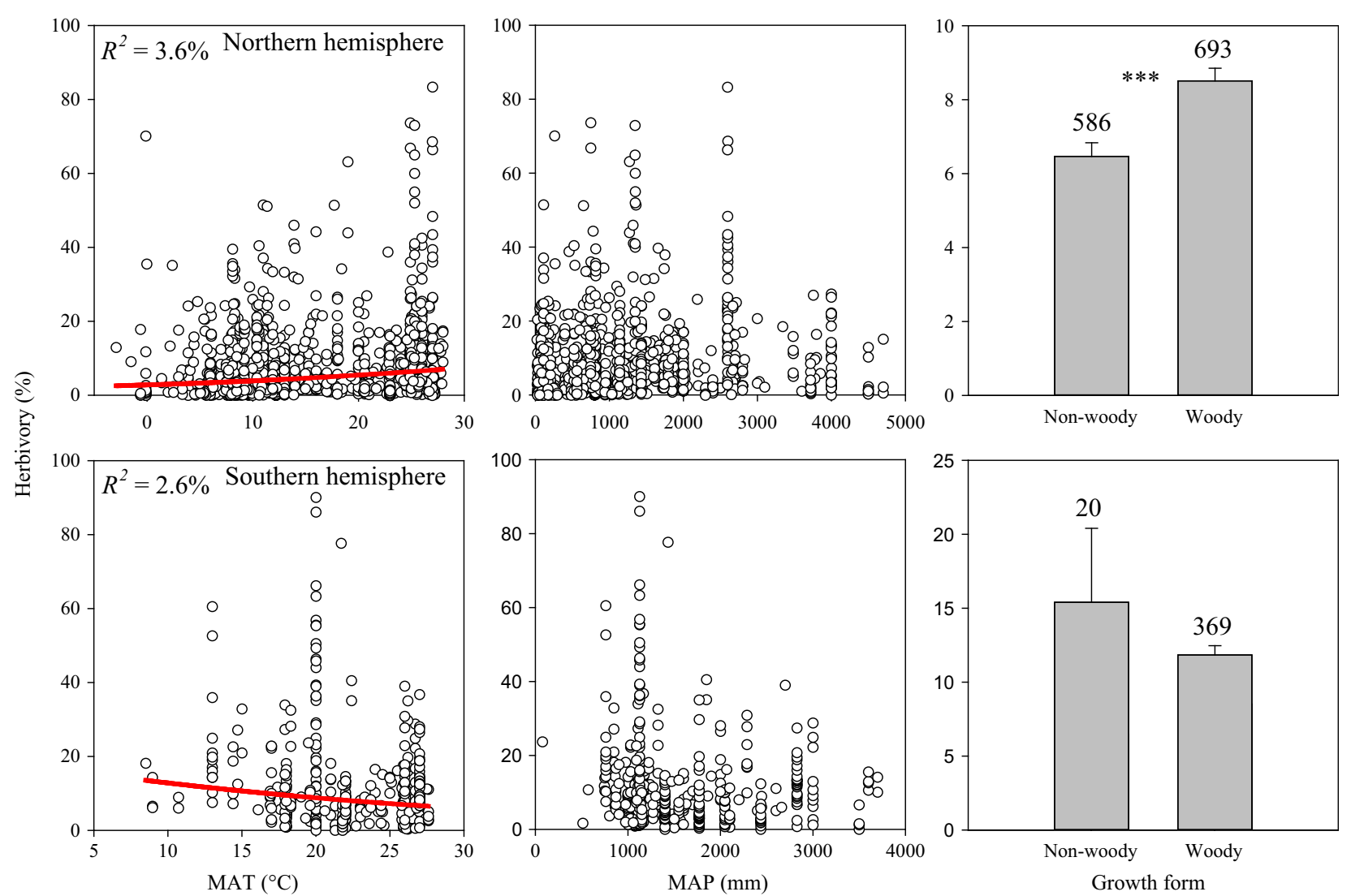

Fig. 3. The relationships of herbivory with mean annual temperature (MAT), mean annual precipitation (MAP) and the growth form of the plant species in the Northern (upper panels) and Southern Hemispheres (lower panels). Numbers on the bar represent samples sizes. $*_{* *}$ denotes $P<0.001$.

2009a; Anstett, Naujokaitis-Lewis \& Johnson 2014; Kim 2014; Moreira et al. 2015). We noticed that the negative effect of latitude on herbivory seems rather weak in the Northern Hemisphere. For example, the mean herbivory level in tropical regions was only $3.3 \%$ higher than in non-tropical regions. Interspecific differences, the specificity of a given study site and many other unknown factors can weaken the effect of latitude on herbivory. Thus, we believe that our study offers a qualitative test of the latitude-herbivory relationship.

We found temperature, but not precipitation, had a significant positive relationship with herbivory in the Northern Hemisphere. Temperature can affect the ontogenetic development, survival, abundance and distribution of herbivores (Bale et al. 2002). Because in sometimes, the plant-herbivore interactions intensify with increasing temperature (O'Connor 2009; Rall et al. 2010; O'Connor, Gilbert \& Brown 2011), this can lead to higher levels of herbivory in the tropics in the Northern Hemisphere. At the temporal scale, a previous palaeoecological study found that insect herbivory has tracked palaeotemperature for six million years (Currano, Labandeira \& Wilf 2010). In combination with this study, it seems that temperature may be one of the key factors that affect the pattern of herbivory, both at larger spatial and temporal scales. Herbivory has been assumed to be related closely to plant defensive traits (Agrawal 2011). However, we found that both the pattern and factors that affect herbivory are very different from those of plant defences. Previous synthetic studies have shown that the leaves of tropical species were not more resistant than those of temperate species (Moles et al. 2011a,b; Onoda et al. 2011) and that precipitation was more important than temperature in affecting the global pattern of mechanical defences in leaves (Onoda et al. 2011). However, another study found that temperature had a strong correlation with leaf traits by comparison with precipitation (Moles et al. 2014). These inconsistent conclusions suggest that the underlying mechanisms that affect the latitudinal patterns of herbivory and plant defences can be different, at least in the Northern Hemisphere. Linking the leaf economics spectrum theory with the LH or LR hypotheses may be crucial to our understanding of the latitudinal patterns of herbivory and plant defences (Donovan et al. 2011).

We also confirmed the pattern that woody plants suffer a higher level of herbivory than do non-woody species (Turcotte et al. 2014a), but also only in the Northern Hemisphere. The plant apparency theory can explain this difference - as for herbivores, woody plants are often more apparent to be located within a community compared to non-woody plants (Feeny 1976; Turcotte et al. 2014a). Another explanation for the patterns we observed is that if tropic species are likely to be evergreen, they will have longer times of exposure to herbivores, thus allowing more herbivory to accumulate. This 
may be also the case for woody species because they may have relative longer leaf life spans than non-woody species. It should be noted that our study included herbivory caused only by leaf-chewing insects. It is possible that other types of herbivory have different latitudinal patterns (Anstett, Naujokaitis-Lewis \& Johnson 2014; Moreira et al. 2015). To evaluate the LH hypothesis fully, herbivory caused by other herbivores (e.g. sap-sucking insects) should not be overlooked, because these herbivores also have strong effects on plants (Zvereva, Lanta \& Kozlov 2010). Ecological network analysis could be a useful method for explaining the pattern of herbivory at large spatial scales in further studies (Lange \& Del-Claro 2014).

In the Southern Hemisphere, herbivory failed to show a relationship with latitude and yet decreased with MAT. These findings are different, and even opposite, to the patterns we found in the Northern Hemisphere. Although statistically seeming to be solid, the results in the Southern Hemisphere should be interpreted with caution. First, the current studies are very biased towards the Northern Hemisphere. Because studies from the Southern Hemisphere never reached further than $42^{\circ}$, no sites have very cold temperatures as in the Northern Hemisphere (Fig. S1). This imbalance in the data set may impede the appearance of a clearer latitude-herbivory relationship in the Southern Hemisphere. Secondly, species in the Southern Hemisphere may have longer leaf life spans, because of the greater prevalence of deciduous leaves in the Northern Hemisphere. This can lead to different latitudinal patterns in plant resistance traits and herbivory (Moles et al. 2011b; Lim, Fine \& Mittelbach 2015). These relatively longer leaf life spans are a likely explanation for the higher level of herbivory in the Southern Hemisphere as we found in this study. Another explanation for our findings is that species richness, which has important effects on herbivory, declined more rapidly in terrestrial ecosystems from the equator in the Northern than in the Southern Hemisphere in terrestrial ecosystems (Chown et al. 2004). The reason for why herbivory decreased with MAT in the Southern Hemisphere is not yet clear. A possible explanation for this pattern is that the higher temperature in lower latitudes in some specific ecosystems (e.g. savanna) in the Southern Hemisphere might suppress the activity of insect herbivores, resulting in lower herbivory levels in this area. However, the possible influences of habitat type on the latitudinal variation of herbivory have not been evaluated. Further studies are needed to test the suitability of the LH hypothesis in the Southern Hemisphere, especially those with study sites at higher latitudes.

In general, we showed that the LH hypothesis is supported only in the Northern Hemisphere, and that, compared to precipitation, temperature is a better predictor of herbivory at the global scale. These results highlight the importance of temperature in mediating the global patterns of a key ecological process. We suggest the possible differences in herbivory between the Northern and Southern Hemispheres, and their underlying mechanisms should not be overlooked in future studies.

\section{Acknowledgements}

We thank Kleber Del-Claro and Angela Moles for their helpful comments and suggestions on the manuscript. This work was supported by National Natural Science Foundation of China $(31300368,31370451)$.

\section{Data accessibility}

All data are uploaded as online Supporting information.

\section{References}

Adams, J.M. \& Zhang, Y.J. (2009) Is there more insect folivory in warmer temperate climates? A latitudinal comparison of insect folivory in eastern North America. Journal of Ecology, 97, 933-940.

Adams, J.M., Rehill, B., Zhang, Y.J. \& Gower, J. (2009a) A test of the latitudinal defense hypothesis: herbivory, tannins and total phenolics in four North American tree species. Ecological Research, 24, 697-704.

Adams, J.M., Zhang, Y.J., Basri, M. \& Shukor, N. (2009b) Do tropical forest leaves suffer more insect herbivory? A comparison of tropical versus temperate herbivory, estimated from leaf litter. Ecological Research, 24, 13811392.

Agrawal, A.A. (2011) Current trends in the evolutionary ecology of plant defence. Functional Ecology, 25, 420-432.

Andrew, N.R. \& Hughes, L. (2005) Herbivore damage along a latitudinal gradient: relative impacts of different feeding guilds. Oikos, 108, 176-182.

Andrew, N.R., Roberts, I.R. \& Hill, S.J. (2012) Insect herbivory along environmental gradients. Open Journal of Ecology, 2, 202-213.

Anstett, D.N., Naujokaitis-Lewis, I. \& Johnson, M.T.J. (2014) Latitudinal gradients in herbivory on Oenothera biennis vary according to herbivore guild and specialization. Ecology, 95, 2915-2923.

Bale, J.S., Masters, G.J., Hodkinson, I.D., Awmack, C., Bezemer, T.M., Brown, V.K. et al. (2002) Herbivory in global climate change research: direct effects of rising temperature on insect herbivores. Global Change Biology, 8, 1-16.

Becerra, J.X. (2015) On the factors that promote the diversity of herbivorous insects and plants in tropical forests. Proceedings of the National Academy of Sciences of the United States of America, 112, 6098-6103.

Chown, S.L., Sinclair, B.J., Leinaas, H.P. \& Gaston, K.J. (2004) Hemispheric asymmetries in biodiversity - a serious matter for ecology. Plos Biology, 2, e406.

Coley, P.D. \& Aide, T.M. (1991) Comparison of Herbivory and Plant Defences in Temperate and Tropical Broad-Leaved Forests, in Plant-Animal Interactions: Evolutionary Ecology in the Tropical and Temperate Regions. John Wiley \& Sons Ltd., Brisbane, Australia.

Coley, P.D. \& Barone, J.A. (1996) Herbivory and plant defenses in tropical forests. Annual Review of Ecology and Systematics, 27, 305-335.

Currano, E.D., Labandeira, C.C. \& Wilf, P. (2010) Fossil insect folivory tracks paleotemperature for six million years. Ecological Monographs, 80, 547-567.

Dobzhansky, T. (1950) Evolution in the Tropics. American Scientist, 38, 209 221.

Donovan, L.A., Maherali, H., Caruso, C.M., Huber, H. \& de Kroon, H. (2011) The evolution of the worldwide leaf economics spectrum. Trends in Ecology \& Evolution, 26, 88-95.

Feeny, P. (1976) Plant apparency and chemical defense. Recent Advances in Phytochemistry, 10, 1-40.

Feller, I.C., Chamberlain, A.H., Piou, C., Chapman, S. \& Lovelock, C.E. (2013) Latitudinal patterns of herbivory in mangrove forests: consequences of nutrient over-enrichment. Ecosystems, 16, 1203-1215.

Gaston, K.J., Genney, D.R., Thurlow, M. \& Hartley, S.E. (2004) The geographical range structure of the holly leaf-miner. IV. Effects of variation in host-plant quality. Journal of Animal Ecology, 73, 911-924.

Ho, L.S.T. \& Ané, C. (2014) A linear-time algorithm for Gaussian and nonGaussian trait evolution models. Systematic Biology, 63, 397-408.

Janzen, D.H. (1970) Herbivores and the number of tree species in tropical forests. American Naturalist, 104, 501-528.

Johnson, M.T.J. \& Rasmann, S. (2011) The latitudinal herbivory-defence hypothesis takes a detour on the map. New Phytologist, 191, 589-592.

Kim, T.N. (2014) Plant damage and herbivore performance change with latitude for two old-field plant species, but rarely as predicted. Oikos, 123, 886-896.

Kozlov, M.V., Zverev, V. \& Zvereva, E.L. (2014) Confirmation bias leads to overestimation of losses of woody plant foliage to insect herbivores in tropical regions. PeerJ, 2, e709. 
Lange, D. \& Del-Claro, K. (2014) Ant-Plant Interaction in a Tropical Savanna: May the Network Structure Vary over Time and Influence on the Outcomes of Associations? PLOS ONE, 9, e105574.

Lim, J.Y., Fine, P.V.A. \& Mittelbach, G.G. (2015) Assessing the latitudinal gradient in herbivory. Global Ecology and Biogeography, 24, 1106-1112.

Lowman, M.D. (1984) An assessment of techniques for measuring herbivory - is rainforest defoliation more intense than we thought. Biotropica, 16, 264-268.

Moles, A.T., Bonser, S.P., Poore, A.G.B., Wallis, I.R. \& Foley, W.J. (2011a) Assessing the evidence for latitudinal gradients in plant defence and herbivory. Functional Ecology, 25, 380-388.

Moles, A.T., Wallis, I.R., Foley, W.J., Warton, D.I., Stegen, J.C., Bisigato, A.J. et al. (2011b) Putting plant resistance traits on the map: a test of the idea that plants are better defended at lower latitudes. New Phytologist, 191, 777 788.

Moles, A.T., Perkins, S.E., Laffan, S.W., Flores-Moreno, H., Awasthy, M., Tindall, M.L. et al. (2014) Which is a better predictor of plant traits: temperature or precipitation? Journal of Vegetation Science, 25, 1167-1180.

Moreira, X., Abdala-Roberts, L., Parra-Tabla, V. \& Mooney, K.A. (2015) Latitudinal variation in herbivory: influences of climatic drivers, herbivore identity and natural enemies. Oikos, 124, 1444-1452.

Nakagawa, S. \& Schielzeth, H. (2013) A general and simple method for obtaining R2 from generalized linear mixed-effects models. Methods in Ecology and Evolution, 4, 133-142.

New, M., Hulme, M. \& Jones, P. (1999) Representing twentieth-century spacetime climate variability. Part I: Development of a 1961-90 mean monthly terrestrial climatology. Journal of Climate, 12, 829-856.

O'Connor, M.I. (2009) Warming strengthens an herbivore-plant interaction. Ecology, 90, 388-398.

O'Connor, M.I., Gilbert, B. \& Brown, C.J. (2011) Theoretical predictions for how temperature affects the dynamics of interacting herbivores and plants. American Naturalist, 178, 626-638.

Onoda, Y., Westoby, M., Adler, P.B., Choong, A.M.F., Clissold, F.J., Cornelissen, J.H.C. et al. (2011) Global patterns of leaf mechanical properties. Ecology Letters, 14, 301-312.

Pearse, I.S. \& Hipp, A.L. (2012) Global patterns of leaf defenses in oak species. Evolution, 66, 2272-2286.

Pennings, S.C., Ho, C.-K., Salgado, C.S., Więski, K., Davé, N., Kunza, A.E. \& Wason, E.L. (2009) Latitudinal variation in herbivore pressure in Atlantic Coast salt marshes. Ecology, 90, 183-195.

Rall, B.C., Vucic-Pestic, O., Ehnes, R.B., Emmerson, M. \& Brose, U. (2010) Temperature, predator-prey interaction strength and population stability. Global Change Biology, 16, 2145-2157.

Rasmann, S. \& Agrawal, A.A. (2011) Latitudinal patterns in plant defense: evolution of cardenolides, their toxicity and induction following herbivory. Ecology Letters, 14, 476-483.

Salazar, D. \& Marquis, R.J. (2012) Herbivore pressure increases toward the equator. Proceedings of the National Academy of Sciences of the United States of America, 109, 12616-12620.

Schemske, D.W., Mittelbach, G.G., Cornell, H.V., Sobel, J.M. \& Roy, K. (2009) Is there a latitudinal gradient in the importance of biotic interactions? Annual Review of Ecology Evolution and Systematics, 40, 245-269.
Sinclair, R.J. \& Hughes, L. (2008) Incidence of leaf mining in different vegetation types across rainfall, canopy cover and latitudinal gradients. Austral Ecology, 33, 353-360.

Travers-Martin, N. \& Muller, C. (2008) Matching plant defence syndromes with performance and preference of a specialist herbivore. Functional Ecology, 22, 1033-1043.

Turcotte, M.M., Davies, T.J., Thomsen, C.J.M. \& Johnson, M.T.J. (2014a) Macroecological and macroevolutionary patterns of leaf herbivory across vascular plants. Proceedings of the Royal Society B-Biological Sciences, 281, 20140555.

Turcotte, M.M., Thomsen, C.J.M., Broadhead, G.T., Fine, P.V.A., Godfrey, R.M., Lamarre, G.P.A., Meyer, S.T., Richards, L.A. \& Johnson, M.T.J. (2014b) Percentage leaf herbivory across vascular plant species. Ecology, 95, 788-788.

Webb, C.O., Ackerly, D.D. \& Kembel, S.W. (2008) Phylocom: software for the analysis of phylogenetic community structure and trait evolution. Bioinformatics, 24, 2098-2100.

Webb, C.O. \& Donoghue, M.J. (2005) Phylomatic: tree assembly for applied phylogenetics. Molecular Ecology Notes, 5, 181-183.

Zhang, S., Zhang, Y. \& Ma, K. (2015) The equal effectiveness of different defensive strategies. Scientific Reports, 5, 13049.

Zvereva, E.L., Lanta, V. \& Kozlov, M.V. (2010) Effects of sap-feeding insect herbivores on growth and reproduction of woody plants: a meta-analysis of experimental studies. Oecologia, 163, 949-960.

Received 14 October 2015; accepted 6 April 2016

Handling Editor: Richard Shefferson

\section{Supporting Information}

Additional Supporting Information may be found in the online version of this article:

Figure S1. The latitudinal patterns and averaged values (Mean, SE) of mean annual temperature (MAT) and precipitation (MAP) in the Northern and Southern hemispheres (Northern hemisphere, positive latitudes; Southern hemisphere, negative latitudes).

Figure S2. Plant herbivory (Mean, SE) in tropical and non-tropical regions in the Northern and Southern hemispheres.

Figure S3. The predicted relationships of latitude and mean annual temperature (MAT) with herbivory by the generalized least squares regression model phylogenetic regression (PGLS) in the Northern and Southern Hemispheres.

Table S1. The dataset used in the study. 